\title{
EL CONSTRUCTIVISMO COMO NUEVA PERSPECTIVA PARA ANALIZAR LAS RELACIONES ENTRE ESTADOS: EL CASO DE LA CRISIS DEL GAS ENTRE BOLIVIA Y CHILE ${ }^{1}$
}

\section{Constructivism as a new perspective to analyze relations between states: The case of the gas crisis between Bolivia and Chile}

\author{
Natalia Lizama *
}

\section{RESUMEN}

En este artículo, a fin de colaborar en la introducción del análisis constructivista a los estudios latinoamericanos, se recogen las principales ideas y conceptos del constructivismo que pueden ayudar a entender que en las relaciones internacionales también influyen los llamados factores ideacionales, como la identidad e intereses, y no sólo los factores materiales. Junto a ello, se dará luces de cómo este enfoque puede ampliar el análisis de la relaciones entre Bolivia y Chile, centrándose en las identidades estatales de ambos países que inciden en las relaciones bilaterales.

Palabras clave: Constructivismo, identidad estatal, relaciones de Bolivia y Chile.

\footnotetext{
* Centro de Estudios de Relaciones Internacionales, Facultad de Gobierno, Universidad del Desarrollo. Santiago, Chile. Correo electrónico: nlizama@udd.cl

${ }^{1}$ Este artículo forma parte del proyecto interno de investigación $\mathrm{N}^{\circ} 23400047$ de la Universidad del Desarrollo, denominado "Chile: de la identidad insular a la política de apertura a Asia Pacífico".

Artículo recibido el 13 de marzo de 2012. Aceptado el 9 de julio de 2013.
} 


\begin{abstract}
This article, in order to collaborate on the inclusion of the constructivist analysis to Latin-American studies, captures the main ideas and concepts about constructivism that can help to understand that international relations are also affected by ideational factors, as identity and interests, and not only by material factors. In addition, it outlines how this approach can broad the analysis of Bolivia and Chile's relations, focusing on the Bolivian and Chilean state identities influencing on bilateral relations.
\end{abstract}

Keywords: Constructivism, state identity, relations of Bolivia and Chile.

\title{
INTRODUCCIÓN
}

Aunque lentamente, el Constructivismo de las Relaciones Internacionales se ha ido incorporando a los estudios latinoamericanos, por ejemplo, en temas relacionados con la integración en América Latina ${ }^{2}$ y política exterior ${ }^{3}$ entre otros. Un fenómeno parecido ha sucedido en la literatura dedicada a la política exterior de Chile, donde se ha podido visualizar la creciente inclusión de factores "no materiales", desde el punto de las Relaciones Internacionales, al análisis de las interacciones entre Chile y sus países vecinos, tales como: los flujos culturales entre zonas fronterizas, ${ }^{4}$ las percepciones mutuas entre estos Estados, ${ }^{5}$ las sensaciones de desconfianza y rivalidad, ${ }^{6}$ y las identidades nacionales como generadoras de limitantes u oportunidades, ${ }^{7}$ entre otros. Dichas variables pertenecen a una dimensión de las relaciones internacionales más bien desatendida por los enfoques dominantes, como el neorrealismo y el neoliberalismo institucional, correspondiente a la dimensión ideacional, esto es, aquellos factores inmateriales o

\footnotetext{
${ }^{2}$ Mujica, María Eugenia. "Globalización en el sur: problemas para sostener y profundizar la integración en América Latina”, Revista Colombia Internacional 40 (1997): 33-36.

${ }^{3}$ Russel, Robert y Tokatlian, Juan Gabriel. "El lugar del Brasil en la política exterior de la argentina: La visión del otro", Desarrollo Económico 42 (2002): 167.

${ }^{4}$ Podestá, Juan. "Regiones fronterizas y flujos culturales: La peruanidad en una región chilena”, Universum 26/1 (2011): 123-137.

${ }^{5}$ Milet, Paz Verónica. “Chile-Perú: Las dos caras de un espejo”, Revista de Ciencia Política 24/2 (2004): 228-235.

${ }^{6}$ Kahhat, Farid. "Las relaciones entre Chile y Perú en el ámbito de la seguridad: entre la cooperacion y la desconfianza", Revista Fuerzas Armadas y Sociedad 1/20 (2006): 3-16, o Wehner, Leslie. "From Rivalry to Mutual Trust: The Othering Process between Bolivia and Chile", GIGA Working Papers 135 (2010): 1-25. Disponible en: <http://papers.ssrn.com/sol3/ papers.cfm?abstract_id=1616642>. [Consultado: el 16 de abril de 2013].

7 Van Der Ree, Gerard. "Chile's (Inter) National Identities: Framing the Relations with Bolivia and Peru”, Bulletin of Latin American Research 29/2 (2010): 208-223, o Colacrai, Miryam. "Las identidades de Chile en sus relaciones internacionales. ¿Entre el paradigma comercialista y el territorialista?”, Revista de Ciencias Sociales, Universidad de Costa Rica IV/122 (2008): 59-70.
} 
cognitivos, tales como las ideas, normas sociales comunes, y otros, que conforman una "estructura normativa", cuyos elementos emanan tanto del contexto nacional como del internacional, y que influyen en la toma de decisiones de la política exterior. Aquellas fuerzas ideacionales están siendo rescatadas por nuevos enfoques teóricos dentro de esta disciplina entre los cuales destaca el constructivismo. Para los constructivistas, las fuerzas del poder no sólo son materiales, sino también son ideacionales: el poder puede entenderse también como "la creación de identidades e intereses que limitan la capacidad de los actores para controlar su destino". 8 Basado, entonces, en que las identidades e intereses influyen en las relaciones internacionales, este enfoque ha sido aplicado para entender, por ejemplo, la anarquía y sus efectos sobre el sistema internacional, la cooperación, sistemas de seguridad y conflictos entre Estados, entre muchos otros temas. A fin de ampliar la comprensión de las ambivalentes relaciones de Chile con sus vecinos, resulta, por tanto, primordial re-direccionar el análisis de la política exterior chilena desde los enfoques materialistas y geopolíticos hacia aquellos que consideran esta dimensión ideacional.

En vista de lo anterior, en este artículo, se pretende dar luces de cómo el constructivismo puede ampliar la comprensión de las relaciones entre Bolivia y Chile, exponiendo los principales elementos que permitan analizar las relaciones bilaterales a partir de la crisis del gas de 2003 y 2004. Con este propósito, primero, se destacarán los conceptos e ideas constructivistas que permiten extender la compresión de las relaciones internacionales; y segundo, se esbozará de qué manera es posible comprender y analizar desde dichos conceptos e ideas fundamentales del enfoque las relaciones de Bolivia y Chile en el caso de la crisis del gas.

\footnotetext{
${ }^{8}$ Barnett, Michael. "Social Constructivism". In John Baylis, Steve Smith \& Patricia Owens (eds.). The Globalization of World Politics: an introduction to international relations. Oxford: Oxford University Press, (2008): 160-173.
} 


\section{ELEMENTOS CONSTRUCTIVISTAS PARA ANALIZAR LAS RELACIONES INTERNACIONALES Y LA POLÍTICA EXTERIOR: LOS FACTORES IDEACIONALES DEL PODER Y LA ESTRUCTURA CULTURAL DE LOS ESTADOS}

Esta perspectiva o "enfoque filosófico-teórico" como sugiere Ruggie" considera las relaciones internacionales como un conjunto de fenómenos socialmente construidos, reclamando así la re-estructuración de las mismas. Para los teóricos constructivistas, las relaciones internacionales son una realidad social, compuesta por hechos sociales que dependen de un acuerdo social y que, por tanto, se dan por hecho; en consecuencia, las relaciones internacionales existirán en la medida en que el acuerdo exista, configurando de esta manera cómo categorizamos el mundo y lo que hacemos. En este sentido, preguntas constructivistas se centran en la esencia de la anarquía y apuntan a resolver si ésta realmente existe o si es producto de ciertas prácticas sociales en un contexto histórico determinado. Al contrario, el neorrealismo intenta resolver los problemas provocados por ella, es decir, determinar de qué manera es posible mitigar los efectos de la anarquía, y el neoliberalismo institucional -por su parte- se pregunta cómo promover y dar soporte a la cooperación.

Para responder a esas interrogantes, a los factores materiales, o "poder material", que influyen en la toma de decisiones de los Estados y en las relaciones entre los actores del sistema internacional, como los recursos militares y económicos -que configuran la estructura o distribución de capacidades del sistema internacional, descritos por los enfoques neorrealistas y neoliberalel constructivismo plantea otro conjunto de variables que conformarían una dimensión paralela a la dimensión material de las relaciones internacionales, correspondiente a la dimensión ideacional, compuesta por los factores ideacionales -o "poder discursivo" en lenguaje de Ted Hopf- los que influyen en las preferencias e intereses de los Estados y, de ahí, en el comportamiento de estos en la arena internacional.

\footnotetext{
${ }_{9}^{9}$ Ruggie, John. "What makes the world hang together? Neo-utilitarianism and the social constructivist challenge". In Peter Katzenstein, Robert Keohane \& Stephen Krasner (eds.). Exploration and Contestation in the Study of World Politics. Cambridge, Massachusetts: MIT Press, (1999): 215-245.
} 


\subsection{Factores ideacionales del poder}

Convencionalmente, el poder se entiende como la capacidad de un actor para lograr que otro actor haga lo que de otra manera no haría. A este concepto de poder, el constructivismo agrega una segunda manera de entenderlo: como "la creación de identidades e intereses que limitan la capacidad de los actores para controlar su destino". ${ }^{10}$ En opinión de los constructivistas, el poder tiene que ver también con "cómo el conocimiento, el establecimiento de significados y la construcción de identidades distribuyen recompensas y capacidades diferenciadas". ${ }^{11}$ La manera como se define a un país desarrollado y a un país subdesarrollado, o qué comportamiento se entiende como legítimo y cuál no otorga facultadas para actuar a unos más que a otros o cataloga a unos países como más poderosos que otros.

Por lo tanto, el constructivismo otorga un sitial central al rol de las ideas en las relaciones internacionales, ideas sociales dentro de las cuales se pueden incluir imágenes mentales, percepciones mutuas, conceptos, significados, categorías, conocimientos, creencias, principios, valores sociales, culturas, símbolos, costumbres y normas sociales comunes -que establecen cuál es el comportamiento "adecuado- en una sociedad determinada y, de esa forma, determinan el devenir de las relaciones internacionales. Según esta lógica, los agentes y sus interacciones ayudan a construir, reproducir y transformar estas ideas sociales o "estructuras" a través de un proceso de socialización constante. Este conjunto de ideas conforma una así llamada "estructura normativa" compuesta por un conocimiento compartido, que es producido históricamente y ligado por la cultura, sobre la base de percepciones de mundo, y que configura cómos los individuos construyen, interpretan y dan significado a la realidad, determinando así sus preferencias. ${ }^{12}$ Para este enfoque, la estructura normativa consiste en un sistema de significados y valores sociales que establecen el comportamiento considerado como legítimo, los cuales no están predeterminados, más bien son generados por la interacción entre los Estados. Esta estructura normativa configura las identidades e intereses de los actores, como los Estados y, de ahí, la estrategia considerada como apropiada, ${ }^{13}$

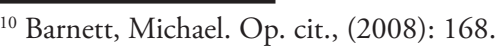

${ }^{11}$ Ibíd., 165.

${ }^{12}$ Ibíd., 163.

${ }^{13}$ Ibíd., 167.
} 
modelando así la dirección de su política exterior.

La identidad es lo que los actores son e incluye aquellas ideas sostenidas por el Yo, o estructura interna, y aquellas ideas sostenidas por el Otro, o estructura externa. ${ }^{14}$ En el caso de un Estado, la "identidad estatal” se podría definir como "un conjunto ampliamente aceptado de representaciones acerca del Estado (por lo general simbólica o metafórica), en especial en su relación con otros Estados, junto con las correspondientes creencias respecto del comportamiento adecuado, derechos y responsabilidades" ${ }^{15} \mathrm{El}$ constructivismo concibe los intereses como socialmente construidos, ya que los actores no tienen una especie de portafolio de intereses que llevan a todas partes con independencia del contexto social; en realidad, los actores van definiendo los intereses en el proceso en que definen las situaciones. ${ }^{16}$ Si la identidad se refiere a quién o qué son los actores, designando categorías sociales o formas de ser, los intereses se refieren a lo que los actores desean, designando así motivaciones que permiten explicar el comportamiento; por ende, sin las identidades los intereses no tienen dirección y sin los intereses las identidades no tienen fuerza motivacional. ${ }^{17}$ A juicio de Wendt, los intereses se escogen a la luz de las identidades y explica que "los intereses presuponen identidades, ya que un actor no puede saber lo que quiere hasta que no sepa quién es, y, como las identidades tienen diversos grados de contenido cultural, los intereses también". ${ }^{18}$

Reconocer que las identidades influyen en el devenir de las relaciones interestatales significa pasar de centrar el análisis en las capacidades de los Estados o en la distribución de poder como una propiedad estructural del sistema internacional a dirigirlo ahora a las identidades de los Estados. Es decir, esto implica "un cambio desde lo que los Estados pueden hacer debido a su posición en una estructura hacia lo que ellos quieren hacer debido a cómo estos se ven a sí mismos en relación con otros". ${ }^{19}$ En voz de Hopf, los factores ideacionales o lo

\footnotetext{
${ }^{14}$ Wendt, Alexander. Social Theory of International Relations. Cambridge: Cambridge University Press, (1999): 224.

${ }^{15}$ Alexandrov, Maxym. "The Concept of State Identity in International Relations: A Theoretical Analysis", Journal of International Development and Cooperation 10/1 (2003): 39.

${ }^{16}$ Wendt, Alexander. "Anarchy is what states make of it", International Organization 46/2 (1992): 398.

${ }^{17}$ Wendt, Alexander. Op. cit., ( 1999): 231.

${ }^{18}$ Ibíd.

${ }^{19}$ Kubálková, Vendulka. "Foreing policy, international politics, and constructivism”. In Vendulka Kubálková. Foreing policy in a constructed world. New York: M. E. Sharpe, (2001a): 33.
} 
que él denomina "poder discursivo" es el poder de la práctica social ${ }^{20}$ y la política exterior sería un tipo de práctica social que constituye y da poder al Estado. ${ }^{21}$ De esta manera, de la literatura constructivista se puede desprender que dentro de las fuerzas ideacionales que influyen en las relaciones internacionales figuran las identidades y los intereses, los que conforman un sistema o estructura cultural interestatal que puede afectar el comportamiento de los Estados. La conformación de estos elementos -las identidades e intereses- se detalla en a continuación.

\subsubsection{Conformación de las identidades e intereses estatales}

El estudio de la identidad como factor que influye en el comportamiento de los Estados y en las relaciones internacionales puede abordarse en tres niveles, según es posible deducir de la literatura constructivista. En un primer nivel nacional o local-, la construcción de la realidad social podría comenzar dentro del propio Estado y ser visible en el o los discursos internos; en un segundo nivel -bilateral-, la realidad se podría construir entre dos Estados; y en un tercer nivel -multilateral o internacional-, la identidad de un Estado y otro se ve influenciada por las normas sociales aprendidas dentro de la comunidad internacional. Aquí se detalla sólo los dos primeros niveles.

\subsubsection{Conformación de las identidades e intereses estatales a nivel nacional}

Las identidades son las causas de las elecciones y reacciones de otros; a partir de ello, Ted Hopf desarrolla una teoría sobre la identidad social y elección en política exterior, poniendo el acento en las estructuras sociales de una sociedad y, dentro de ella, el lenguaje -y el discurso- como mecanismo creador de la estructura cognitiva social, formadas por las identidades. Hopf parte de la premisa de que las identidades sólo pueden ser entendidas relacionalmente; no es posible saber qué es una identidad sin relacionarla con otra ${ }^{22}$ y los discursos dan cuenta precisamente de cómo los individuos se consideran a sí mismos y a otros comúnmente, estableciendo así una realidad intersubjetiva dentro de un Estado. El propósito de estudiar los discursos es descubrir en ellos cómo se

\footnotetext{
${ }^{20}$ Hopf, Ted. "The promise of constructivism in International Relations Theory", International Security 23/1 (1998): 171-200.

${ }^{21}$ Ashley, Richard. "Foreign policy as political performance". In: International Studies Notes, 1988 extraído de Hopf (1998).

${ }^{22}$ Hopf, Ted. Social Construction of International Politics: Identities and Foreign Policies. New York: Cornell University Press, (2002): 7.
} 
producen las identidades populares y, de ahí, los intereses de un Estado. Para Hopf, una identidad o conjunto de identidades presentes dentro de una formación discursiva constituyen al Estado y determinan los intereses de un Estado frente a otros. Este autor constructivista estudia lo que denomina "estructura social cognitiva" de una sociedad determinada, que prevalece en un tiempo y espacio determinado, consistente en una red de significados intersubjetiva, "stock social de conocimiento", hábitos o espacio temporal socio-histórico determinado dentro del que predominan ciertos significados que establecen la forma en que los individuos comúnmente piensan de ellos mismos y de los demás. ${ }^{23}$ Dentro de una misma estructura social cognitiva, Hopf sitúa las formaciones discursivas que contienen las identidades que influyen en los tomadores de decisión de un Estado.

\subsubsection{Conformación de las identidades e intereses estatales a nivel bilateral}

Para Wendt, la formación de estructuras sociales, identidades, intereses y normas sociales se desarrolla a partir del contacto intersubjetivo entre los Estados o lo que más atrás se denominó estructura normativa, dentro de un proceso de aprendizaje social o de socialización. Según Wendt, la identidad del Yo debe ser aceptada por el Otro, por lo tanto, este proceso de socialización tiene dos dimensiones: el significado que el Yo se atribuye a sí mismo (la auto-comprensión) y la percepción que el Otro tiene del Yo (que es, por tanto, intersubjetiva). Ambas dimensiones pasan a formar parte del conocimiento compartido o "cultura". Este conocimiento compartido o conjunto de significados colectivos es lo que comprendemos o esperamos del Otro o lo que constituye las concepciones del Yo y el Otro, y, a su vez, lo que conforman las estructuras que organizan nuestras acciones. Las relaciones entre Estados dependen de cómo un Estado categorice al otro, si lo concibe como su amigo o su enemigo, adecuándose el actuar de ambos a dicha forma de categorización intersubjetiva. Esto se explica en que -así como las personas- los Estados actúan hacia otros actores sobre la base de los significados que estos tienen para ellos. Ello explicaría por qué el crecimiento de China como potencia militar es motivo de inquietud en Taiwán o por qué la compra de equipamiento militar por el Estado chileno provoca preocupación en Perú o Bolivia.

${ }^{23}$ Ibíd., 5 y 6. 


\subsection{La estructura cultural y las relaciones entre estados}

El constructivismo considera las identidades y los intereses como factores que influyen en la toma de decisiones en política exterior, ya que estos pueden abrir o cerrar las posibilidades de una relación cooperativa o conflictiva en virtud del tipo de estructura cultural que se haya construido entre los actores. La perspectiva constructivista entiende el interés y la identidad estatal como un elemento endógeno a la interacción, vale decir, son variables dependientes, no dadas, por lo que se pueden transformar ${ }^{24}$, difiriendo así de los enfoques dominantes, que asumen que el Estado actúa en función de un interés predeterminado por la lógica de la anarquía, lo que implica considerarlo como un elemento exógeno al Estado; teniendo esta premisa, la identidad pasa a ser irrelevante a la hora de comprender las relaciones interestatales. Los intereses que los actores poseen, derivados tanto de las identidades como de las normas sociales internacionales, determina las oportunidades de cooperación. En consecuencia, el constructivismo pondrá énfasis en los aspectos cognitivos de la cooperación y no meramente en los aspectos conductuales de ella, puesto que existe una estructura de identidades e intereses que se inician en la interacción misma, una estructura definida por el conocimiento intersubjetivo. ${ }^{25}$ Bajo este punto de vista, los Estados egoístas pueden aprender a cooperar al reconstruir sus intereses y del establecimiento de compromisos compartidos con las normas sociales. ${ }^{26}$

Para el constructivismo, la anarquía es construida socialmente por efecto de los significados colectivos. ${ }^{27}$ Conforme explica Wendt, "los procesos de formación de identidad bajo anarquía están vinculados primero que todo con la preservación o 'seguridad' del Yo. Por lo tanto, los conceptos de seguridad difieren en la medida y según la manera que el Yo se identifica con el Otro", ${ }^{28}$ diferencias cognitivas de las cuales dependen el significado que tenga la anarquía y la distribución del poder. ${ }^{29}$ En consecuencia, -a los tres elementos que determinan la estructura del sistema internacional y, de ahí, el comportamiento de los actores según Kenneth

\footnotetext{
${ }^{24}$ Kubálková, Vendulka. "Soviet 'new thinking and the end of cold war: Five explanations”. In Vendulka Kubálková. Foreing policy in a constructed world. New York: M. E. Sharpe, (2001b): 122.

${ }^{25}$ Wendt, Alexander, Op. cit., 417.

${ }^{26}$ Ibíd.

${ }^{27}$ Kubálková, Vendulka, Op. cit., (2001b): 122.

${ }^{28}$ Wendt, Alexander, Op. cit., 399.

${ }^{29}$ Ibíd., 400.
} 
Waltz -a saber: la anarquía, la diferenciación funcional de las unidades y la distribución de capacidades materiales- Wendt agrega un cuarto: la "estructura constituida intersubjetivamente por identidades e intereses del sistema" o, simplemente, "estructura cultural". Esta estructura cultura o social "consiste en el stock entrelazado de creencias, ideas, comprensión, percepciones, identidades o [...] 'conocimiento', que poseen los miembros del sistema" ${ }^{30}$. Entonces, los sistemas de autoayuda -el competitivo y el individualista- se reproducen debido a que existen identidades competitivas y egoístas que causan tal inseguridad: "los sistemas de seguridad de autoayuda evolucionan a partir de ciclos de interacción donde cada parte actúa según siente al otro como una amenaza creando así la expectativa de que en el otro no se debe confiar". ${ }^{31}$ En otras palabras, son las identidades competitivas y egoístas las que dan cabida a la gestación del dilema de seguridad, que perpetúa la desconfianza y la alienación.

Así, Wendt identifica tres 'estructuras culturales' o simplemente 'culturas' que pueden existir en el sistema internacional: las culturas hobbesiana, lockeana y kantiana; se trata de ideas o conocimiento compartido, esto es, manifestaciones de la comprensión respecto del uno y del otro que constituyen la base para un sistema que puede ser tanto cooperativo como conflictivo. Estas ideas compartidas determinan una posición o postura particular en cada actor, lo que Wendt denomina 'rol estructural'32 (o role structure), es decir, aquella "configuración de las posiciones subjetivas que entregan las ideas compartidas a quienes las poseen". ${ }^{33}$ Este rol no es un atributo de los agentes o actores ni tampoco las creencias del actor; es, en realidad, un atributo de la estructura. ${ }^{34}$ Así, Wendt establece tres roles estructurales o posturas en cada una de las culturas mencionadas: en una cultura hobbesiana, el rol estructural de los agentes es de "enemigo"; en la cultura lockeana, es de "rival"; y, en la cultura kantiana, es de "amigo". ${ }^{35}$

\footnotetext{
${ }^{30}$ Cita de Ruben, David-Hillel. The Metaphysics of the Social World. New York: Penguin, 1985. Extraída de Wendt, Alexander. "Identity and structural change in international politics". In Yosep Lapid, \& Frederich Kratochwil (eds.). The return of culture and identity in IR theory. London: Lynne Reinner Publishers, (1996): 49.

${ }^{31}$ Ibíd., 406.

${ }^{32}$ Traducción propia.

${ }^{33}$ Wendt, Alexander, Op. cit., (1999): 257.

${ }^{34}$ Ibíd., 257 y 258.

${ }^{35}$ Wendt describe dichos roles: amigo, rival y enemigo en Wendt (1999: 259).
} 


\section{ELEMENTOS CONSTRUCTIVISTAS PARA ANALIZAR LAS RELACIONES DE BOLIVIA Y CHILE}

En esta sección, se esbozará de qué manera es posible comprender y analizar desde los conceptos e ideas fundamentales del enfoque constructivista las relaciones de Bolivia y Chile a partir de la crisis del gas del año 2003 y 2004, identificando la conformación de las identidades e intereses de los Estados chileno y boliviano que confluyen en este contexto y repercuten en la relación bilateral.

La así llamada crisis del gas entre Bolivia y Chile tiene relación con la crisis diplomática producida entre el gobierno de Ricardo Lagos de Chile y los gobiernos de Gonzalo Sánchez de Lozada y Carlos Mesa de Bolivia, quien tuvo como objetivo sellar el acuerdo que Jorge Quiroga había elaborado junto a Ricardo Lagos durante el año 2002 para la exportación del gas licuado de petróleo boliviano a través de un puerto chileno, que se había suspendido debido a la oposición de la población boliviana a la exportación del gas natural por puerto chileno. ${ }^{36}$ Durante su administración, Sánchez de Lozada emprende una serie de negociaciones con el consorcio Pacific LNG (formado por la española Repsol YPF, British Energy y Panamerican Energy) para enviar el gas a Estados unidos y México vía Chile. ${ }^{37}$ Sin embargo, el conocimiento por parte de la población de los planes del gobierno puso en marcha en septiembre de 2003 una ola de protesta lideradas por Evo Morales del Movimiento al Socialismo (MAS) y Felipe Quispe del Movimiento Indígena Pachacuti (MIP) con el objetivo de frenar la política neoliberal de Sánchez de Lozada, que pretendía -según los dirigentes privar al país de sus reservas de gas vendiéndolas a bajo precio a Estados Unidos. De esta manera, hacia octubre de ese año había 20.000 manifestantes en las calles, La Paz estaba a punto de sumirse en la revuelta popular y las protestas amenazaban con extenderse a los demás departamentos del país. ${ }^{38}$ En medio de este caos, Sánchez de Lozada decidió dejar en suspenso los planes sobre el gas y el 17 de octubre renunció al cargo frente a las fuertes presiones de la población levantada. El ex mandatario sería sucedido por Carlos Mesa, el cual prometió convocar a referéndum vinculante para determinar si se exporta o no el gas, el

\footnotetext{
${ }^{36}$ Revista Ercilla, "Bolivia, Algo más que una guerra del gas", No 3.225, del 29 de septiembre al 12 de octubre, 2003.

${ }^{37}$ Assies, Willem. "Bolivia: A gasified democracy", Revista Europea de Estudios Latinoamericanos y del Caribe 76, abril, (2004): 25-39.

${ }^{38}$ The Economist, "On the brink", 18 de octubre de 2003; y The Economist, "Highly flammable", 13 de septiembre de 2003.
} 
que arrojo la negativa de la ciudadana boliviana a la exportación del gas por Chile. $^{39}$

\subsection{Conformación de las identidades e interés estatales de Bolivia y Chile que influyen en la relación bilateral}

En consideración de contexto de la crisis del gas, el análisis de las relaciones bilaterales bajo la óptica del constructivismo en los términos planteados aquí requiere identificar aquellos elementos ideacionales observables en la relación a nivel discursivo, distinguiéndose, al menos, dos pares de identidades contrapuestas que influyeron en las relaciones bilaterales: las identidades territorialista y neoliberal, en el caso chileno, y las identidades revisionista y antineoliberal, en el caso boliviano.

\subsubsection{Identidades territorialista y revisionista}

El primer par de identidades contrapuestas que gatilló la crisis del gas fue la territorialista, del Estado chileno, y la revisionista, en el caso boliviano, ya que tanto Jorge Quiroga en 2000 como Carlos Mesa en 2004 intentaron convertir en moneda de cambio para exportar el gas boliviano por puerto chileno ya sea una franja costera en concesión sin soberanía -según lo solicitado por Quiroga- o un acceso útil y soberano al mar -conforme lo exigió Mesa-. Por su parte, el gobierno chileno mantuvo su postura tradicional vis à vis la demanda marítima boliviana de respeto irrestricto de la soberanía e integridad territorial nacional.

Esta postura del gobierno de Chile tiene sus antecedentes en el hecho de que haber resultado victorioso en la Guerra del Pacífico se convirtió en un acto fundacional para el Estado chileno y de su identidad nacional, ${ }^{40}$ creando así un excesivo orgullo nacional en la población chilena y una victoria que representó un triunfo sobre el antiguo y poderoso virreinato del Perú, ${ }^{41}$ configurando a nivel nacional una identidad marcada por la noción del 'territorio'. Colacrai identifica ciertos "nudos" en las relaciones de Chile con Bolivia y con Perú que señalan la

\footnotetext{
${ }^{39}$ The Economist, "After the uprising", 25 de octubre de 2003; y Camargo, Vanesa. "Bolivia y Chile después del Referéndum", América Economía, del viernes 30 de julio de 2004. Disponible en: <http://www.americaeconomica.com/numeros4/276/reportajes/vanesa276.htm>. [Consultado: el 8 de mayo de 2013].

${ }^{40}$ Wehner, Leslie, Op. cit., (2010): 13.

${ }^{41}$ Milet, Paz, Op. cit, (2004): 235.
} 
vigencia de esta identidad territorialista y la indefinición de límites geográficos, que tienen que ver con la "asignación de 'cualidad marítima' a Bolivia [...], sin que ello signifique otorgarle soberanía, y la disputa que ha ido creciendo en relación con los espacios marítimos con Perú...”. ${ }^{2}$

En la relación con Bolivia, la Guerra del Pacífico contribuyó a conformar determinadas imágenes mutuas y percepciones geopolíticas contrapuestas. La invasión chilena, la pérdida de territorio e, incluso, la obtención de trofeos de guerra crearon percepciones negativas del Otro y categorías del Yo y el Otro contrapuestas. Así, Chile resultó ser el país vencedor, mientras que Bolivia (y también Perú), los países vencidos; Chile como país invasor, y Bolivia (y Perú) como los países invadidos; la pérdida territorial afectó a Bolivia pero no a Chile, lo que convirtió a éste último en el país ganador y al otro, en el perdedor. Chile si bien ganó la categoría de gran potencia político-militar en la región esto fue a costa de ganar la imagen de un país agresivo y expansionista. Bolivia, por su parte, ha proyectado frente a la comunidad internacional, según explica el académico boliviano Fernando Salazar, una imagen de país víctima del expansionismo chileno desde aquel conflicto armado. ${ }^{43}$

La estrategia de Mesa de emplear el gas como moneda de cambio despertó, al mismo tiempo, la identidad legalista de Chile. Como es sabido en el plano internacional, Chile se caracteriza por mantener una postura categórica de respeto de la intangibilidad de los tratados y un estricto apego a la ley y al derecho internacional, al resguardo de la soberanía nacional y a la no intromisión en los asuntos internos de un Estado. ${ }^{44}$ A juicio de Van Der Ree, la identidad legalista ha complejizado, a la vez, sus vínculos con sus vecinos ${ }^{45}$, puesto que, debido al respeto irrestricto del derecho internacional y de los tratados internacionales, los gobiernos chilenos han mantenido la postura de que el Tratado de Paz y Amistad de 1904 resolvió la demarcación limítrofe y, por tanto, no existiría controversia alguna con Bolivia. Sin embargo, según explica Antonio Araníbar, Bolivia no pone en entredicho los argumentos jurídicos del tratado, más bien pone el acento en la dimensión política, histórica y económica debido a los daños que la condición mediterránea ha significado para este país. ${ }^{46}$

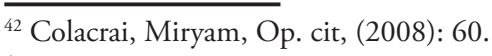

${ }^{43}$ Salazar, Fernando. Hacia una nueva politica exterior boliviana. La Paz: Ediciones CERID, 2000.

${ }^{44}$ Van Der Ree, Gerard, Op. cit., (2010): 215.

${ }^{45}$ Ibíd., 216.

${ }^{46}$ Araníbar, Antonio. "Memoria corta de un antiguo diferendo", Revista Nueva Sociedad 190, marzo-abril, (2004): 4-13.
} 


\subsubsection{Identidades neoliberal y antineoliberal}

El segundo par de identidades confrontadas que encendió la crisis del gas fue la neoliberal y la antineoliberal, para Chile y Bolivia, respectivamente, en razón de que la crisis terminó con suspender definitivamente el proyecto de exportación del gas boliviano por un puerto chileno, una iniciativa comercial que beneficiaba a ambos países. Junto con ello, además de suspenderse las acciones para seguir avanzando en un TLC entre Bolivia y Chile, ${ }^{47}$ el gobierno de Mesa incorporó en el contrato de venta del hidrocarburo a Argentina de abril de 2004 una cláusula especial que prohibió a este país revender el gas boliviano a Chile, ${ }^{48}$ lo que a su vez genera una grave crisis energética en Chile.

Dentro del nivel nacional de la conformación de la identidad y autopercepciones del Estado boliviano, se considera la construcción de una idea de Estado de orientación antineoliberal, que se comienza a gestar durante la crisis de gobernabilidad generada durante el gobierno de Sánchez de Lozada en 2003 y se concreta en el gobierno de Evo Morales desde 2006, de tendencia izquierda nacionalista e indigenista, y ligado al llamado "Socialismo del siglo XXI". En efecto, las demandas planteadas durante las manifestaciones de 2003 apuntaban a rechazar las políticas de privatización de las empresas del Estado que tendían a beneficiar a empresas mayormente estadounidenses ${ }^{49} \mathrm{y}$ a demandar que de la propiedad de los hidrocarburos volviera a las manos del Estado boliviano y la no exportación por puerto chileno, sino por uno peruano, a pesar de que era más costosa. En general, la sociedad boliviana rechaza el modelo económico neoliberal que agravó la corrupción, arruinó a las poblaciones e incrementó la exclusión social de los indígenas y clases bajas..$^{50}$ En el contexto de la exportación de gas, los bolivianos se opusieron fuertemente a la inversión extranjera en los recursos naturales del país, debido a la exportación de las riquezas naturales (plata, estaño, petróleo) nunca mejoró la situación de los pobres ni permitió el desarrollo económico y modernización del país, por lo que Bolivia sigue dependiendo de la ayuda extranjera. ${ }^{51}$

\footnotetext{
${ }^{47}$ Yopo, Martina. "Una focalización equivocada de esfuerzos", Revista Nueva Sociedad/190, marzo-abril, (2004): 14-21.

${ }^{48}$ Camargo, Vanesa. "Bolivia pretende que Chile cambie 'gas por mar' ", América Economía, del viernes 25 de junio de 2004. Disponible en: < http://www.americaeconomica.com/numeros4/271/reportajes/2vanesa271.htm>. [Consultado: el 12 de mayo de 2013].

${ }^{49}$ Revista Ercilla, "Bolivia, Algo más que una guerra del gas”, Op. cit., 2003.

${ }^{50}$ Ramonet, Ignacio. "Bolivia”, Le Monde Diplomatique, noviembre del 2003.

${ }^{51}$ Ibíd.
} 
En el caso chileno, dentro del nivel nacional de la conformación de la identidad y auto-percepciones, figuran las imágenes que la elite empresarial chilena ha intentado proyectar hacia fuera de las fronteras, como un país exitoso y modelo para el resto de los países latinoamericanos. Conforme explica Van Der Ree, esta visión de Estado se sustenta material y discursivamente. Lo material se refiere al éxito del modelo de mercado y economía abierta desarrollado por la política exterior de Chile desde fines de 1970, que ha priorizado las relaciones económicas con sus países vecinos, a través de acuerdos comerciales. A nivel discursivo, esta identidad también se expresa en que "las elites políticas y económicas del país montaron un poderoso discurso que describe a Chile como un 'jaguar' o como un 'milagro", 52 "relato empresarial" en el que se insertaron categorías para referirse al país tales como "modelo" o "país superior", e, incluso, con posibilidades de convertirse en un país desarrollado en 2021, reforzando así la tendencia de las cúpulas chilenas a diferenciarse de su entorno latinoamericano.

A nivel bilateral, esta identidad neoliberal también es recreada y tiene un efecto en las relaciones con los países vecinos, puesto que ha contribuido a intensificar las percepciones de Chile en estos países como un actor imperialista. Van Der Ree identifica tres interpretaciones ligadas a esta identidad chilena que puede efectuar Bolivia. La primera es la de imperialismo histórico, vinculada al expansionismo chileno del siglo XIX, que -además de entregarle territoriosle entregó riqueza gracias a la explotación del salitre de la zona. Y la segunda interpretación es la de una forma de explotación económica, a causa de los efectos negativos en Bolivia del comercio con Chile. ${ }^{53}$

Ambos conjuntos de identidades terminaron fundiéndose en el contexto de la crisis del gas. En efecto, la negativa de la ciudadanía boliviana de exportar gas por un puerto chileno hizo surgir un fuerte nacionalismo en Bolivia y el reclamo de que Chile tendría una deuda histórica que debía pagar por la pérdida del territorio tras el Tratado de 1904; el boliviano común y corriente nunca se ha olvidado de que Chile les haya arrebatado la costa del Pacífico, incluyendo la región de Patillos en la guerra de $1879 .{ }^{54}$ Las repercusiones sobre las relaciones bilaterales consistieron en el abandono definitivo de las tratativas para la exportación del gas

\footnotetext{
${ }^{52}$ Van Der Ree, Gerard, Op. cit., (2010): 213.

${ }^{53}$ Ibíd., 214.

${ }^{54}$ The Economist , "Highly flammable", 13 de septiembre de 2003.
} 
por puerto chileno, del cual la alternativa más económica según Pacific LNG era Patillos, ${ }^{55}$ y en la multilateralización de la demanda marítima nuevamente en la Organización de Estados Americanos (OEA), cuando se cumplía el centenario de la firma del Tratado de 1904, lo que, a su vez significaba el cambio de un perfil más bien moderado desde comienzos de los años 90 hasta 2003 a uno más ofensivo desde 2004 en el plano multilateral, ${ }^{56}$ aunque sin los efectos que tuvo la demanda marítima en la OEA en los años 80.

\section{LA 'ESTRUCTURA CULTURAL' DE LA RELACIÓN ENTRE BOLIVIA Y CHILE SEGÚN EL CONSTRUCTIVISMO}

Este conjunto de formas de autopercepción o formas de percibir al Otro y las identidades del Estado chileno que se despertaron con ocasión de la crisis del gas han incidido en las relaciones de Bolivia y Chile al determinar en parte la definición de los intereses que se perseguirán en materia de política exterior configura una estructural intersubjetiva cultural o social determinada. Siguiendo la clasificación de estructura cultural de Wendt -hobbesiana, lockeana o kantianapodríamos identificar en cierta medida las relaciones de Bolivia y Chile con una estructura cultural lockeana en términos wendtianos, donde el rol estructural que cumplen estos Estados es el de rival al mantener entre ellos una posición o postura de competidores. Si bien en esta estructura cultural, según la concibe Wendt, los actores involucrados no funcionan bajo la lógica de "matar o ser matado" propia de la estructura hobbesiana, se pueden generar algunas disputas que involucran fronteras. ${ }^{57}$ Como es sabido, Bolivia ha mantenido una postura revisionista por la demanda boliviana por una salida soberana al mar, empeorada al no existir relaciones diplomáticas formales con Bolivia desde 1978. Mientras que en una cultura hobbesiana, el Yo no le otorga el derecho a existir al Otro -considerado como su enemigo-, adoptando una postura profundamente revisionista ("deep" revisionism), en una cultura lockeana, el Otro sí tiene derecho a existir y adopta una postura revisionista pero "opacada" ("shallow" revisionism), donde el Yo sólo "revisa" o cuestiona el comportamiento y la propiedad del Otro. ${ }^{58}$

\footnotetext{
${ }^{55}$ Ibíd.

${ }^{56}$ Yopo, Martina, Op. cit., (2004): 14-21.

${ }^{57}$ Wendt, Alexander, Op. cit., (1999): 280.

${ }^{58}$ Ibíd.
} 
Dentro de las implicancias que esta estructura social tiene para la política exterior, figura el hecho de que el poder militar relativo es relevante aún, ya que los rivales saben que el Otro podría usar la fuerza para resolver las disputas. Ejemplo de la importancia del poder militar relativo para Chile es su gasto militar, mayor en proporción al PIB de Chile en comparación con sus países vecinos. Esto responde a que las hipótesis de conflicto por lo menos hasta comienzos de los años noventa preveían la posibilidad de tener que enfrentarse con Perú, Bolivia y Argentina de manera simultánea. ${ }^{59}$

\section{CONCLUSIONES}

En este análisis se mostró de qué manera la configuración de las identidades estatales territorialista y neoliberal del Estado chileno y las identidades revisionista y antineoliberal del Estado boliviano influyeron en las relaciones bilaterales con ocasión de la crisis del gas de 2003 y 2004. De aquí se podría desprender que la tendencia de estos países a superar sus respectivas capacidades militares, generando el dilema de seguridad que existe hoy entre Chile y Bolivia responde no necesariamente al efecto de la anarquía del sistema internacional, sino más bien al efecto de las percepciones, imágenes antagónicas e identidades que crean un sistema de seguridad competitivo entre ambos países. Asimismo, las identidades e intereses de Bolivia y Chile han conformado una cultura lockeana en términos wendtianos, pues, primer, Bolivia adopta una postura revisionista "opacada" al cuestionar la soberanía de Chile sobre parte de su territorio de la zona norte por parte de Bolivia. Segundo lugar, porque el poder militar relativo es relevante aún, ya que los rivales saben que el Otro podría usar la fuerza para resolver las disputas. $\mathrm{Y}$, tercero, porque estos actores comparten una comprensión en particular de "cómo se hacen las cosas" o de cómo llevar sus relaciones, sobre la base de la idea de que el Otro no es alguien en quien se puede confiar y, por tanto, es necesario protegerse de él.

\footnotetext{
${ }^{59}$ Kahhat, Farid, Op. cit., (2006): 6.
} 


\section{REFERENCIAS}

Alexandrov, Maxym. "The Concept of State Identity in International Relations: A Theoretical Analysis", Journal of International Development and Cooperation. 10/1 (2003): 33-46.

Araníbar, Antonio. "Memoria corta de un antiguo diferendo", Revista Nueva Sociedad 190, marzo-abril, (2004): 4-13.

Ashley, Richard. "Foreign policy as political performance". In: International Studies Notes, 1988, extraído de Hopf (1998).

Assies, Willem. "Bolivia: A gasified democracy", Revista Europea de Estudios Latinoamericanos y del Caribe 76, abril, (2004): 25-39.

Barnett, Michael. "Social Constructivism". In John Baylis, Steve Smith \& Patricia Owens (eds.). The Globalization of World Politics: An introduction to international relations. Oxford: Oxford University Press, (2008): 160-173.

Camargo, Vanesa. "Bolivia pretende que Chile cambie 'gas por mar'”, América Economia, del viernes 25 de junio de 2004. Disponible en: < http://www. americaeconomica.com/numeros4/271/reportajes/2vanesa271.htm $>$. [Consultado: el 12 de mayo de 2013].

" "Bolivia y Chile después del Referéndum”, América Economía, del viernes 30 de julio de 2004. Disponible en: <http://www.americaeconomica. com/numeros4/276/reportajes/vanesa276.htm>. [Consultado: el 8 de mayo de 2013].

Colacrai, Miryam. "Las identidades de Chile en sus relaciones internacionales. ¿Entre el paradigma comercialista y el territorialista?”, Revista de Ciencias Sociales, Universidad de Costa Rica IV/122 (2008): 60.

Hopf, Ted. "The promise of constructivism in International Relations Theory", International Security 23/1 (1998): 171-200. 
Social Construction of International Politics: Identities and Foreign Policies, New York: Cornell University Press, 2002.

Kahhat, Farid. "Las relaciones entre Chiley Perú en el ámbito dela seguridad: entrela cooperacion y la desconfianza”, Revista Fuerzas Armadas y Sociedad 1/20 (2006): 3-16.

Kubálková, Vendulka. "Foreing policy, international politics, and constructivism". In Vendulka Kubálková (ed.). Foreing policy in a constructed world. New York: M. E. Sharpe, (2001a): 15-37.

"Soviet 'new thinking and the end of cold war: Five explanations". In Vendulka Kubálková (ed.). Foreing policy in a constructed world. New York: M. E. Sharpe, $2001 b$.

Milet, Paz Verónica. "Chile-Perú: Las dos caras de un espejo”, Revista de Ciencia Politica 24/2 (2004): 228-235.

Mujica, María Eugenia. "Globalización en el sur: problemas para sostener y profundizar la integración en América Latina”, Revista Colombia Internacional 40 (1997): 33-36.

Podestá, Juan. "Regiones fronterizas y flujos culturales: La peruanidad en una región chilena", Universum 26/1 (2011): 123-137.

Ramonet, Ignacio. "Bolivia”, Le Monde Diplomatique, noviembre del 2003.

Revista Ercilla, "Bolivia, Algo más que una guerra del gas", No 3.225, del 29 de septiembre al 12 de octubre, 2003.

Ruben, David-Hillel. The Metaphysics of the Social World. New York: Penguin, 1985.

Ruggie, John. "What makes the world hang together? Neo-utilitarianism and the social constructivist challenge". In Peter Katzenstein, Robert Keohane \& Stephen Krasner (eds.). Exploration and Contestation in the Study of World Politics. The MIT Press. Cambridge, Massachusetts y London, (1999): 215-245. 
Russel, Robert y Tokatlian, Juan Gabriel. "El lugar del Brasil en la política exterior de la argentina: la visión del otro”, Desarrollo Económico 42 (2002): 167.

Salazar, Fernando. Hacia una nueva politica exterior boliviana. La Paz: Ediciones CERID, 2000.

The Economist, "On the brink", 18 de octubre de 2003.

The Economist, "Highly flammable", 13 de septiembre de 2003.

The Economist, "After the uprising", 25 de octubre de 2003.

Van Der Ree, Gerard. "Chile's (Inter) National Identities: Framing the Relations with Bolivia and Peru", Bulletin of Latin American Research 29/2 (2010): 208-223.

Wehner, Leslie. "From Rivalry to Mutual Trust: The Othering Process between Bolivia and Chile", GIGA Working Papers 135, (2010): 1-25. Disponible en: <http://papers.ssrn.com/sol3/papers.cfm?abstract_id=1616642>. [Consultado: el 16 de abril de 2013].

Wendt, Alexander. "Anarchy is what states make of it", International Organization 46/2, (1992): 391-425.

"Identity and structural change in international politics". In Yosep Lapid, \& Frederich Kratochwil (eds.). The return of culture and identity in IR theory. London: Lynne Reinner Publishers, (1996).

Social Theory of International Relations. Cambridge: Cambridge University Press, 1999.

Yopo, Martina. "Una focalización equivocada de esfuerzos", Revista Nueva Sociedadl190, marzo-abril, (2004): 14-21. 